\title{
Peroxidase-like activity of nanocrystalline cobalt selenide and its application for uric acid detection
}

\author{
This article was published in the following Dove Press journal: \\ International Journal of Nanomedicine \\ 20 April 2017 \\ Number of times this article has been viewed
}

\author{
Quan-Quan Zhuang' \\ Zhi-Hang Lin' \\ Yan-Cheng Jiang' \\ Hao-Hua Deng ${ }^{2}$ \\ Shao-Bin $\mathrm{He}^{1,3}$ \\ Li-Ting $\mathrm{Su}^{4}$ \\ Xiao-Qiong $\mathrm{Shi}^{2}$ \\ Wei Chen ${ }^{2}$ \\ 'Department of Pharmacy, Affiliated \\ Quanzhou First Hospital of Fujian \\ Medical University, Quanzhou, \\ ${ }^{2}$ Department of Pharmaceutical \\ Analysis, School of Pharmacy, \\ Fujian Medical University, Fuzhou, \\ ${ }^{3}$ Department of Pharmacy, Quanzhou \\ Infectious Disease Hospital, \\ ${ }^{4}$ Department of Pharmaceutical \\ Analysis, Quanzhou Medical College, \\ Quanzhou, People's Republic of China
}

Correspondence: Wei Chen Department of Pharmaceutical Analysis, School of Pharmacy, Fujian Medical University, Fuzhou 350004, People's Republic of China

Tel/fax +8659122862016

Email chenandhu@I63.com

\begin{abstract}
Dendrite-like cobalt selenide nanostructures were synthesized from cobalt and selenium powder precursors by a solvothermal method in anhydrous ethylenediamine. The as-prepared nanocrystalline cobalt selenide was found to possess peroxidase-like activity that could catalyze the reaction of peroxidase substrates in the presence of $\mathrm{H}_{2} \mathrm{O}_{2}$. A spectrophotometric method for uric acid (UA) determination was developed based on the nanocrystalline cobalt selenide-catalyzed coupling reaction between $N$-ethyl- $N$-(3-sulfopropyl)-3-methylaniline sodium salt and 4-aminoantipyrine (4-AAP) in the presence of $\mathrm{H}_{2} \mathrm{O}_{2}$. Under optimum conditions, the absorbance was proportional to the concentration of UA over the range of $2.0-40 \mu \mathrm{M}$ with a detection limit of $0.5 \mu \mathrm{M}$. The applicability of the proposed method has been validated by determination of UA in human serum samples with satisfactory results.
\end{abstract}

Keywords: enzyme mimics, cobalt selenide, peroxidase-like activity, uric acid, human serum

\section{Introduction}

As efficient biological catalysts, enzymes are involved in almost all biological reactions. Besides their important roles in vivo, enzymes are also widely used in biomedical, chemical, food, environmental, and agricultural sciences. In spite of their high substrate specificities and catalytic efficiencies, most natural enzymes can be digested by proteases as they are globular proteins. Their catalytic activities can be easily suppressed under extreme conditions because the protein structure can be disrupted by environmental changes, such as heating or addition of chemical denaturants. Accordingly, it is highly appealing to search for natural enzyme mimics with good stability and low cost.

In clinical analysis, various enzymes are used for the detection of trace amounts of important components in biological samples. As one of the most commonly used biomedical testing tools, peroxidase can catalyze redox reactions between electron donors and $\mathrm{H}_{2} \mathrm{O}_{2}$. The use of chromogenic, fluorescent, and chemiluminescent electron donors with horseradish peroxidase (HRP) has proven highly useful for detecting $\mathrm{H}_{2} \mathrm{O}_{2}$ and tracking reactions that produce $\mathrm{H}_{2} \mathrm{O}_{2}$. In addition, peroxidase-labeled immunoglobulin is a common probe in immunohistochemistry and in enzyme amplification immunoassay systems. However, as with other enzymes, stability is a major problem that restricts the application of peroxidase. A short-term stability test shows that HRP shows dramatically decreased catalytic ability over a few hours at room temperature and loses most of its activity after $24 \mathrm{~h}$. ${ }^{1}$ Since the pioneering study reported by Gao et $\mathrm{al}^{2}$ that showed that magnetic $\mathrm{Fe}_{3} \mathrm{O}_{4}$ nanoparticles exhibit intrinsic peroxidase-like activity, increasing attention has been paid to nanoscale peroxidase mimics such as $\mathrm{V}_{2} \mathrm{O}_{5}$ nanowires, ${ }^{3}$ bimetallic Fe-Co alloy nanoparticles, ${ }^{4}$ cupric oxide nanoparticles, ${ }^{5}$ 
porous platinum nanoparticles on graphene oxide, ${ }^{6}$ graphene quantum dots, ${ }^{7}$ citrate-capped platinum nanoparticles, ${ }^{8} \mathrm{AgX}$ nanoparticles, ${ }^{9}$ platinum nanoparticles in bovine serum albumin scaffold, ${ }^{10}$ and gold nanoparticles. ${ }^{11,12}$ Nanoscale peroxidase mimics possess several advantages over naturally occurring peroxidase enzymes, including almost-unchanged catalytic activity over a wide range of $\mathrm{pH}$ and temperatures, low cost, tunable catalytic activities, as well as ease of storage and treatment. These features make nanoscale peroxidase mimics suitable candidates for potential applications in the fields of biomedicine and environmental chemistry. ${ }^{13-15}$ Humans lack the enzyme uricase, which results in uric acid (UA; 2,6,8-trihydroxypurine) being the end product of purine metabolism in vivo. ${ }^{16}$ Abnormal UA levels are a risk factor for diseases such as hyperuricemia, gout, and urate nephropathy. Thus, it is of great importance to establish simple and effective analytical methods for measuring UA in biofluids for physiological investigations, health assessment, and disease diagnosis. To date, an assortment of analytical methods for determining UA levels in biological samples have been proposed, such as fluorescence, ${ }^{17}$ chemiluminescence, ${ }^{18}$ electrochemistry, ${ }^{19}$ high-performance liquid chromatography, ${ }^{20}$ and capillary electrophoresis. ${ }^{21}$ Colorimetric chemosensors based on nanozymes have also attracted considerable attention for UA detection because of their simplicity and feasibility, as well as the fact that there is no requirement for sophisticated instrumentation..$^{22,23}$

Cobalt selenide nanostructures have proven to be active catalysts for oxygen and hydrogen evolution reactions owing to the suitable electronic configuration of their Co ions. ${ }^{24,25}$ In this work, we study the peroxidase-like catalytic activity of nanocrystalline cobalt selenide that was obtained via solvothermal synthesis. The as-synthesized nanocrystalline cobalt selenide can catalyze the oxidation of peroxidase substrates in the presence of $\mathrm{H}_{2} \mathrm{O}_{2}$, resulting in a color change. This new type of enzyme mimic shows a much higher affinity for $\mathrm{H}_{2} \mathrm{O}_{2}$ than either HRP or other peroxidase mimics. A spectrophotometric method for UA determination was developed based on the nanocrystalline cobalt selenide-catalyzed coupling reaction between $N$-ethyl$N$-(3-sulfopropyl)-3-methylaniline sodium salt (TOPS) and 4-aminoantipyrine (4-AAP) in the presence of $\mathrm{H}_{2} \mathrm{O}_{2}$. The optimum $\mathrm{pH}$ for the nanocrystalline cobalt selenide-catalyzed TOPS/4-AAP- $\mathrm{H}_{2} \mathrm{O}_{2}$ reaction system was 8.5 , which is the same as the optimum $\mathrm{pH}$ for uricase activity. Thus, our proposed approach avoids the process of $\mathrm{pH}$ adjustment after the uricase reaction, which is necessary in previously reported methods using 3,3',5,5'-tetramethylbenzidine (TMB) as a colorimetric substrate. ${ }^{22,23}$ The proposed method was successfully applied to the determination of UA in human serum samples. Thus, we believe that this colorimetric UA sensor will have potential clinical applications in the future.

\section{Experimental Chemicals and reagents}

TOPS, 4-AAP, TMB, o-dianisidine dihydrochloride, 2-amino-2-(hydroxymethyl)-1,3-propanediol (Tris), cobalt powder, selenium powder, UA, triglyceride, cholesterol, creatinine, ascorbic acid, and glucose were all purchased from Aladdin Reagent Company (Shanghai, China). Uricase was purchased from Sigma-Aldrich Co, Ltd (St Louis, MO, USA). $\mathrm{H}_{2} \mathrm{O}_{2}(30 \%)$ was purchased from Sinopharm Chemical Reagent Co, Ltd (Shanghai, China). All chemicals from commercial sources were of analytical grade and were used without further purification. Water was purified using a Milli-Q ${ }^{\circledR}$ system (EMD Millipore, Billerica, MA, USA).

\section{Apparatus}

Ultraviolet/visible (UV/vis) absorption spectra were obtained with a UV-2450 UV/vis spectrophotometer (Shimadzu, Kyoto, Japan). Transmission electron microscopy (TEM) images were collected with a Tecnai G2 F20 microscope (FEI, Hillsboro, OR, USA) at an accelerating voltage of $200 \mathrm{kV}$ at room temperature.

\section{Synthesis of nanocrystalline cobalt selenide}

Nanocrystalline cobalt selenide was synthesized via a previously reported solvothermal method. ${ }^{26}$ Briefly, cobalt powder $(2 \mathrm{mmol})$ and one equivalent of selenium powder were ground together in an agate roller. The precursors and anhydrous ethylenediamine $(27 \mathrm{~mL})$ were added to a Teflon-lined autoclave and heated at $140^{\circ} \mathrm{C}$ for $12 \mathrm{~h}$. A black product was collected, and it was washed with absolute ethanol three times, then dried at $60^{\circ} \mathrm{C}$ for $4 \mathrm{~h}$ before further characterization.

\section{Peroxidase-like activity of nanocrystalline cobalt selenide}

Typically, $200 \mu \mathrm{L}$ of nanocrystalline cobalt selenide $(1.3 \mathrm{mg} / \mathrm{mL}), 250 \mu \mathrm{L}$ of TOPS $(3.2 \mathrm{mM}), 300 \mu \mathrm{L}$ of 4 -AAP $(21 \mathrm{mM})$, and $1.0 \mathrm{~mL}$ of $\mathrm{H}_{2} \mathrm{O}_{2}(0.5 \mathrm{mM})$ were added to $2.25 \mathrm{~mL}$ of Tris- $\mathrm{HCl}$ buffer solution $(50 \mathrm{mM}, \mathrm{pH}=8.5)$. The resulting solution was incubated in a water bath at $40^{\circ} \mathrm{C}$ for $10 \mathrm{~min}$. The absorption of the purple product at $550 \mathrm{~nm}$ was measured using a Shimadzu UV-2450 spectrophotometer. 


\section{UA assays}

UA solutions were prepared in Tris- $\mathrm{HCl}$ buffer solution ( $50 \mathrm{mM}, \mathrm{pH}=8.5$ ). UA determination was carried out as follows: $10 \mu \mathrm{L}$ of uricase $(100 \mathrm{U} / \mathrm{mL})$ was added to $200 \mu \mathrm{L}$ of UA solution (various concentrations). The resulting solution was incubated in a water bath at $40^{\circ} \mathrm{C}$ for $10 \mathrm{~min}$. Subsequently, $3.04 \mathrm{~mL}$ of Tris-HCl buffer solution (50 mM, $\mathrm{pH}=8.5), 250 \mu \mathrm{L}$ of TOPS (3.2 mM), $300 \mu \mathrm{L}$ of 4-AAP $(21 \mathrm{mM})$, and $200 \mu \mathrm{L}$ of nanocrystalline cobalt selenide $(1.3 \mathrm{mg} / \mathrm{mL})$ were added to the reaction and incubated in a water bath at $40^{\circ} \mathrm{C}$ for $30 \mathrm{~min}$. The absorption of the resulting solution at $550 \mathrm{~nm}$ was measured using a UV-2450 UV/vis spectrophotometer (Shimadzu). The detection limit was estimated from three times the standard deviation of the background signals.

\section{Detection of UA in human serum samples}

Clinical human serum samples were donated by the Affiliated Quanzhou First Hospital of Fujian Medical University (Quanzhou, China). The serum samples were diluted 40 times and pretreated by ultrafiltration (Millipore, $3 \mathrm{kDa}$ ). The subsequent procedure for UA analysis was the same as that used for standard UA solutions. The recoveries of UA were determined using spiked samples. This study was approved by the Medical Ethics Committee of the Affiliated Quanzhou First Hospital of Fujian Medical University. Participants signed an informed consent before the experiment, and the information of the volunteers was kept confidential.

\section{Results and discussion \\ Peroxidase-like activity of nanocrystalline cobalt selenide}

Nanocrystalline cobalt selenide was synthesized via a solvothermal method in anhydrous ethylenediamine using cobalt and selenium powders as precursors. ${ }^{26}$ The TEM images (Figure 1) reveal that the as-prepared cobalt selenide consisted of dendrite-like nanostructures.

$\mathrm{H}_{2} \mathrm{O}_{2}$-mediated oxidative coupling of TOPS with 4-AAP was used to investigate the peroxidase-like activity of nanocrystalline cobalt selenide. As shown in Figure 2A, nanocrystalline cobalt selenide could catalyze the reaction to produce a purple color with an absorbance maximum at $550 \mathrm{~nm}$. In contrast, a negligible color change occurred in the absence of the catalyst, suggesting the peroxidaselike activity of the nanocrystalline cobalt selenide. Similar experiments were also performed using other peroxidase substrates in place of TOPS/4-AAP. As shown in Figure 2B,

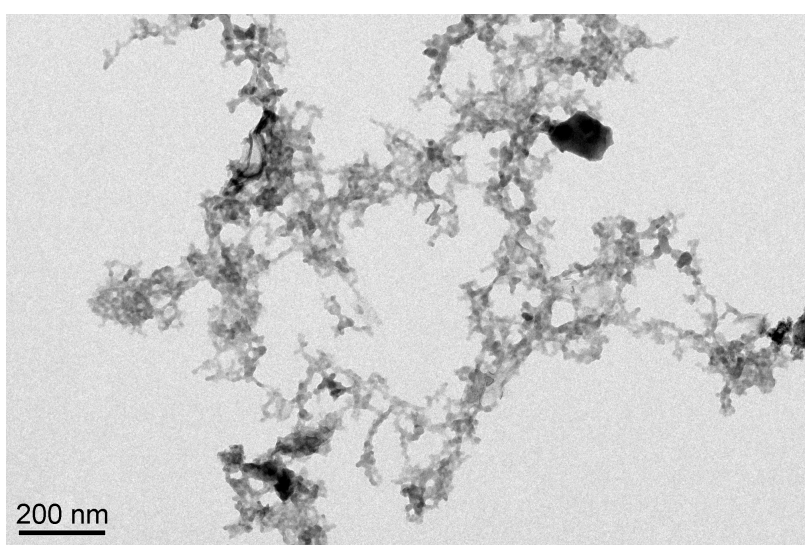

Figure I TEM image of the as-prepared cobalt selenide. Abbreviation: TEM, transmission electron microscopy.

the nanocrystalline cobalt selenide could also catalyze the oxidation reactions of other peroxidase substrates such as TMB and $o$-dianisidine in the presence of $\mathrm{H}_{2} \mathrm{O}_{2}$.

The catalytic activity of nanocrystalline cobalt selenide was further investigated using enzyme kinetics principles and methods. The apparent steady-state kinetic parameters were obtained by varying the $\mathrm{H}_{2} \mathrm{O}_{2}$ concentration, while maintaining the other factors as constant. Figure 3 shows the effect of $\mathrm{H}_{2} \mathrm{O}_{2}$ concentration on reaction rate, with the dots representing the experimental data and the solid curve showing the fitting to the Michaelis-Menten model for enzyme kinetics. The results show that typical MichaelisMenten curves can be obtained for the reaction over the investigated concentration ranges. The apparent $K_{\mathrm{m}}$ value (the substrate concentration at which the reaction rate is half of the maximum) is $72.2 \mu \mathrm{M}$, which is significantly lower than that of HRP, ${ }^{27}$ suggesting that this new enzyme mimic has an affinity for $\mathrm{H}_{2} \mathrm{O}_{2}$ that is at least an order of magnitude higher than that of the natural enzyme.

\section{Optimization of experimental conditions}

As with peroxidase, the catalytic activity of nanocrystalline cobalt selenide is dependent on the reaction temperature and $\mathrm{pH}$. The peroxidase-like activity of the nanocrystalline cobalt selenide was investigated by varying the reaction temperature from $25^{\circ} \mathrm{C}$ to $50^{\circ} \mathrm{C}$. As can be seen from Figure $4 \mathrm{~A}$, the absorbance of the reaction system gradually increased as the reaction temperature increased to $40^{\circ} \mathrm{C}$. However, the catalytic activity of nanocrystalline cobalt selenide plateaued once the reaction temperature crossed $40^{\circ} \mathrm{C}$. This makes the catalytic system suitable for combination with various oxidase-related biological reactions at physiological temperature. The $\mathrm{pH}$ is another important parameter that affects catalytic efficiency. Figure 4B displays the effect of 


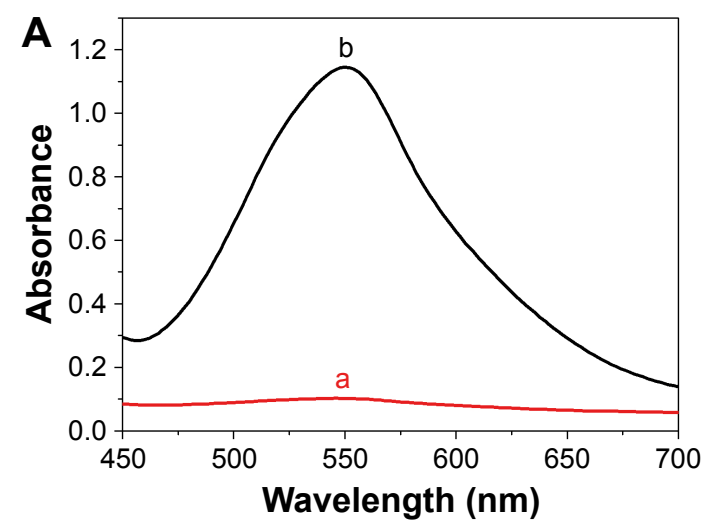

B
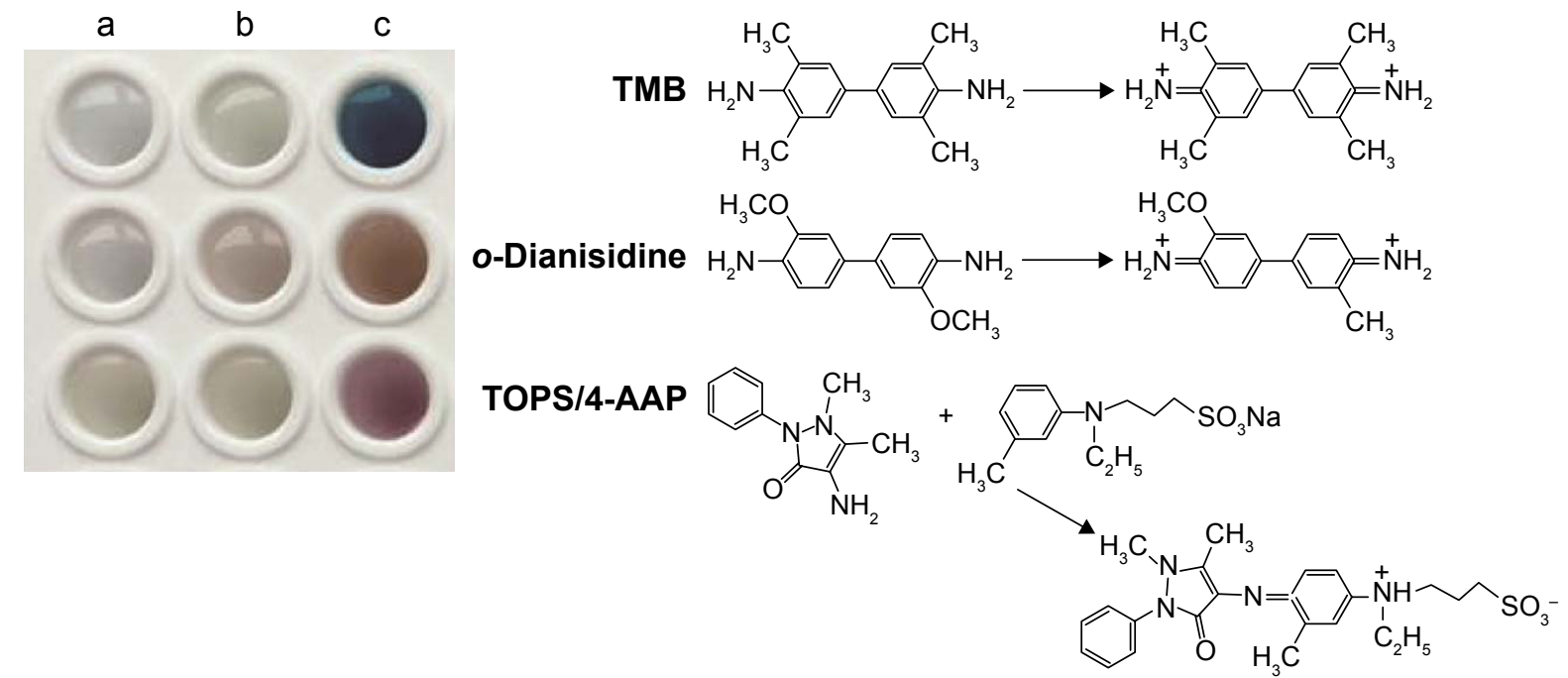

Figure 2 Peroxidase-like activity of nanocrystalline cobalt selenide.

Notes: (A) UV/vis spectra of solutions containing TOPS (0.2 mM), 4-AAP (I.58 mM), and $\mathrm{H}_{2} \mathrm{O}_{2}(\mathrm{I} 25 \mu \mathrm{M})$ (a) in the absence of nanocrystalline cobalt selenide and (b) in the presence of nanocrystalline cobalt selenide $(0.065 \mathrm{mg} / \mathrm{mL})$. (B) Reaction and typical photographs of common chromogenic peroxidase substrates being catalytically oxidized by nanocrystalline cobalt selenide in the presence of $\mathrm{H}_{2} \mathrm{O}_{2}$. (a) Substrate only, (b) substrate $+\mathrm{H}_{2} \mathrm{O}_{2}$, and (c) substrate $+\mathrm{H}_{2} \mathrm{O}_{2}+$ nanocrystalline cobalt selenide.

Abbreviations: 4-AAP, 4-aminoantipyrine; TMB, 3,3',5,5'-tetramethylbenzidine; TOPS, N-ethyl-N-(3-sulfopropyl)-3-methylaniline sodium salt; UV/vis, ultraviolet/visible.

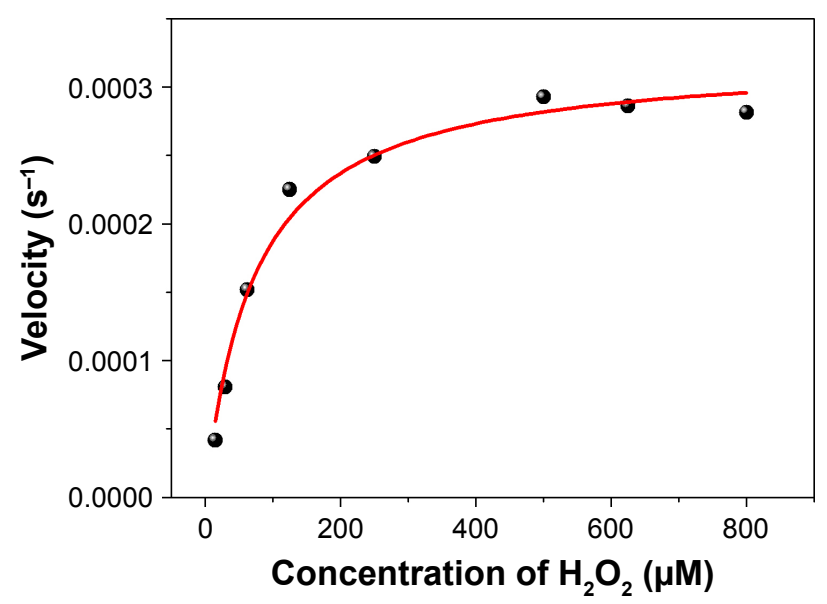

Figure 3 Steady-state kinetic assay for nanocrystalline cobalt selenide. Notes: Experiments were carried out in Tris- $\mathrm{HCl}$ buffer solution $(50 \mathrm{mM}, \mathrm{pH}=8.5)$ at $40^{\circ} \mathrm{C}$. The concentrations of TOPS, 4-AAP, and nanocrystalline cobalt selenide were fixed at $0.2 \mathrm{mM}, 1.58 \mathrm{mM}$, and $65 \mu \mathrm{g} / \mathrm{mL}$, respectively. The concentration of $\mathrm{H}_{2} \mathrm{O}_{2}$ was varied from 15 to $800 \mu \mathrm{M}$.

Abbreviations: 4-AAP, 4-aminoantipyrine; TOPS, N-ethyl-N-(3-sulfopropyl)-3methylaniline sodium salt; Tris, 2-amino-2-(hydroxymethyl)-I,3-propanediol.
$\mathrm{pH}$ on the catalytic activity of nanocrystalline cobalt selenide. Unlike the 2,2'-azino-bis(3-ethylbenzothiazoline-6-sulfonic acid) diammonium salt (ABTS) or the TMB system, the nanocrystalline cobalt selenide-catalyzed TOPS/4-AAP system can be successfully performed at $\mathrm{pH} 8.5$, which is the optimum $\mathrm{pH}$ for uricase activity. This makes the herein-investigated system interesting for the investigation of multienzyme assays with uricase.

To maximize the activity of nanocrystalline cobalt selenide, the effects of varying concentrations of the substrates were also investigated. The relationship between the color intensity of the product and the concentration of TOPS was investigated between 0.04 and $0.4 \mathrm{mM}$. It can be seen from Figure $4 \mathrm{C}$ that the slope at low TOPS concentrations is much steeper than that at higher concentrations. In the former region, product formation could be limited by the quantity of TOPS available in the system. At higher concentrations of TOPS 
A

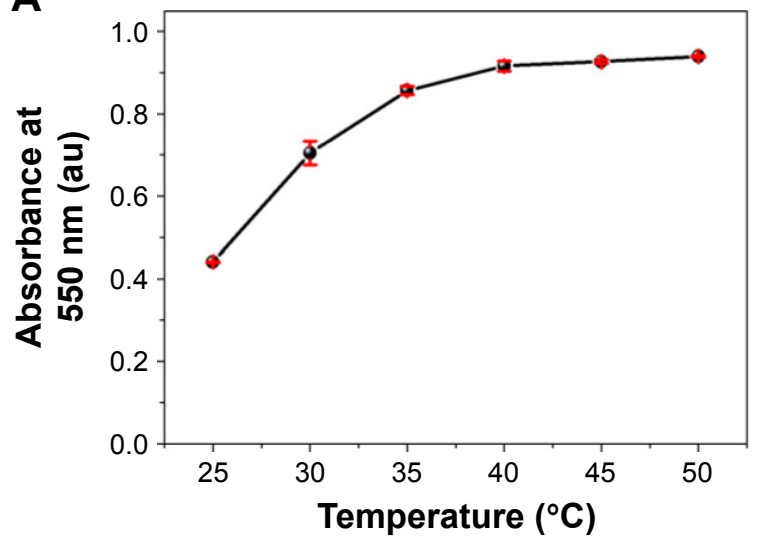

C

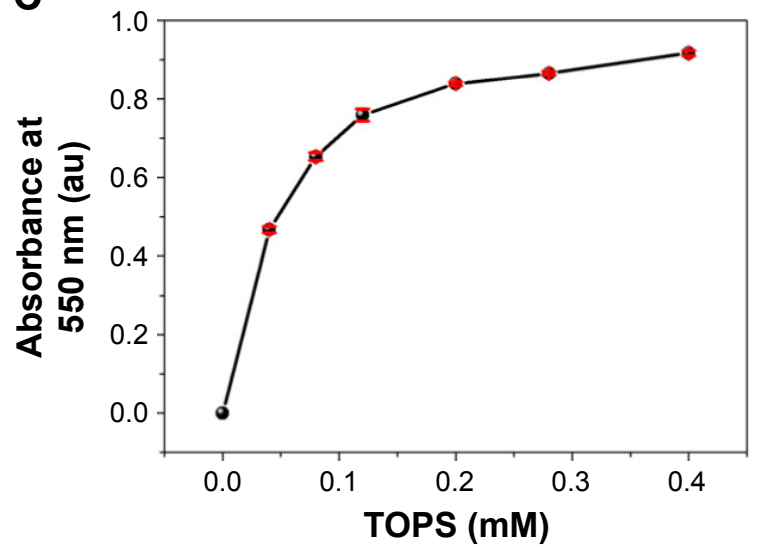

E

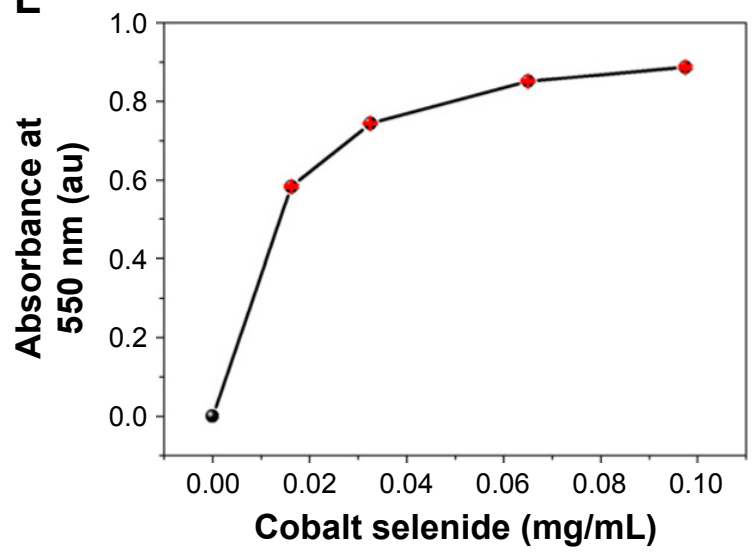

B

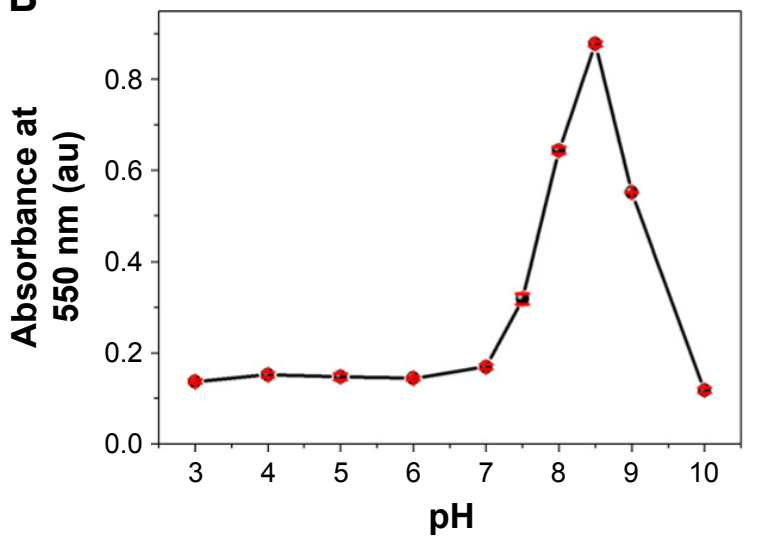

D

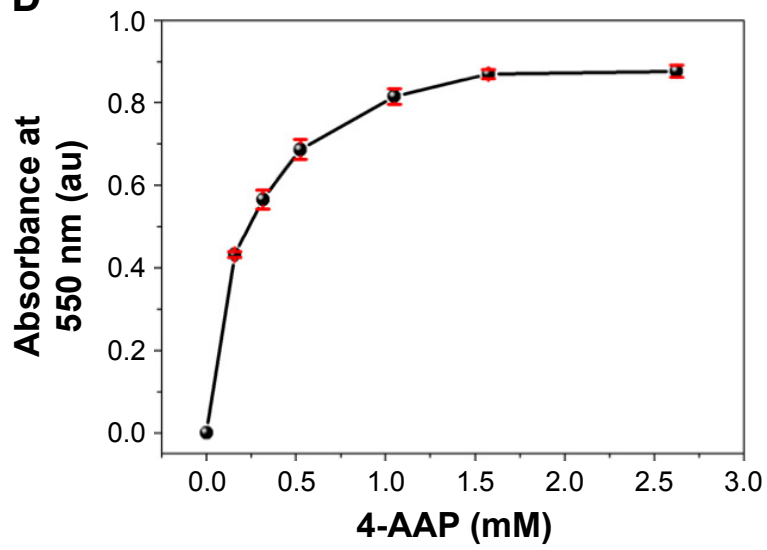

$\mathbf{F}$

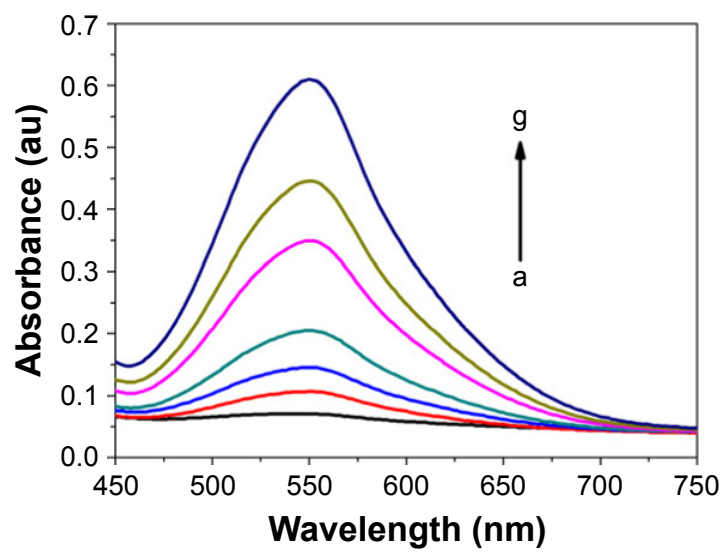

Figure 4 Catalytic activity of nanocrystalline cobalt selenide.

Notes: (A) Temperature dependence of the absorption of a system containing $0.2 \mathrm{mM}$ TOPS, $1.58 \mathrm{mM} \mathrm{4-AAP,} 0.125 \mathrm{mM} \mathrm{H}_{2} \mathrm{O}_{2}$, and $65 \mu \mathrm{g} / \mathrm{mL}$ nanocrystalline cobalt selenide at $550 \mathrm{~nm}$. (B) $\mathrm{pH}$ dependence of the absorption of a system containing $0.2 \mathrm{mM}$ TOPS, $1.58 \mathrm{mM} 4-\mathrm{AAP}, 0.125 \mathrm{mM} \mathrm{H}_{2} \mathrm{O}_{2}$, and $65 \mu \mathrm{g} / \mathrm{mL}$ nanocrystalline cobalt

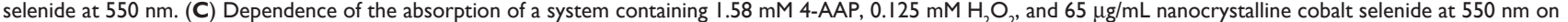

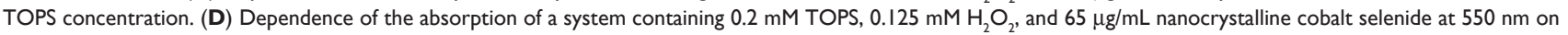
4-AAP concentration. (E) Dependence of the absorption of a system containing $0.2 \mathrm{mM}$ TOPS, $1.58 \mathrm{mM} 4-\mathrm{AAP}$, and $0.125 \mathrm{mM} \mathrm{H}_{2} \mathrm{O}_{2}$ at $550 \mathrm{~nm}$ on nanocrystalline cobalt selenide concentration. (F) Response to $\mathrm{H}_{2} \mathrm{O}_{2}$ based on peroxidase-like activity of nanocrystalline cobalt selenide. $\mathrm{H}_{2} \mathrm{O}_{2}$ concentrations (a-g): $0,8, \mathrm{I}$, 20, 40, 50, and 70 $\mu \mathrm{M}$. The reaction system contained $0.2 \mathrm{mM}$ TOPS, $1.58 \mathrm{mM}$ 4-AAP, $0.125 \mathrm{mM} \mathrm{H}_{2} \mathrm{O}_{2}$, and $65 \mu \mathrm{g} / \mathrm{mL}$ nanocrystalline cobalt selenide.

Abbreviations: 4-AAP, 4-aminoantipyrine; TOPS, N-ethyl-N-(3-sulfopropyl)-3-methylaniline sodium salt.

$(>0.2 \mathrm{mM})$, the absorbance of the system reaches a plateau. A similar investigation was also conducted on the effect of 4-AAP concentration. As shown in Figure 4D, the absorbance of the system was enhanced as the concentration of 4-AAP increased to $1.58 \mathrm{mM}$, after which it was almost constant.
The amount of nanocrystalline cobalt selenide also affected the chromogenic reaction. Because a higher concentration of nanocrystalline cobalt selenide catalyzed the oxidation of the substrates more rapidly, a higher proportion of the product was present in the tested solution. 
As indicated in Figure 4E, the absorbance was rapidly enhanced with increasing nanocrystalline cobalt selenide concentration, reaching a plateau at levels $>0.065 \mathrm{mg} / \mathrm{mL}$. Therefore, a nanocrystalline cobalt selenide concentration of $0.065 \mathrm{mg} / \mathrm{mL}$ was chosen as the standard condition for subsequent analysis. Under the optimum reaction conditions $(0.065 \mathrm{mg} / \mathrm{mL}$ nanocrystalline cobalt selenide, $1.58 \mathrm{mM}$ 4-AAP, $0.2 \mathrm{mM}$ TOPS, $\mathrm{pH} 8.5$, and $40^{\circ} \mathrm{C}$ ), the absorbance was found to be proportional to the concentration of $\mathrm{H}_{2} \mathrm{O}_{2}$ (Figure 4F), which enables the use of the system as a colorimetric sensor for $\mathrm{H}_{2} \mathrm{O}_{2}$ determination.

\section{Detection of UA}

As $\mathrm{H}_{2} \mathrm{O}_{2}$ is the main product of the uricase-catalyzed reaction, the nanocrystalline cobalt selenide-catalyzed oxidative coupling of TOPS/4-AAP can be combined with the uricase catalysis of UA to provide a colorimetric method for the detection of UA (Scheme 1). As shown in Figure 5, a purple product with a maximum absorbance at $550 \mathrm{~nm}$ was formed when the product of the reaction between uricase and UA was introduced into the nanocrystalline cobalt selenidecatalyzed system. The results show that both uricase and UA were essential for the production of the colorimetric product, because the exclusion of either component would yield no $\mathrm{H}_{2} \mathrm{O}_{2}$.

The absorbance increased markedly as the concentration of UA was increased. A linear calibration graph was obtained between 2.0 and $40 \mu \mathrm{M}$ (Figure 6A). The correlation coefficient was 0.998 , and the limit of detection obtained for the experiment was $0.5 \mu \mathrm{M}$ (signal/noise ratio=3). The relative standard deviation for six repeated measurements using $30 \mu \mathrm{M}$ UA was $3.2 \%$. The analytical performance of the proposed
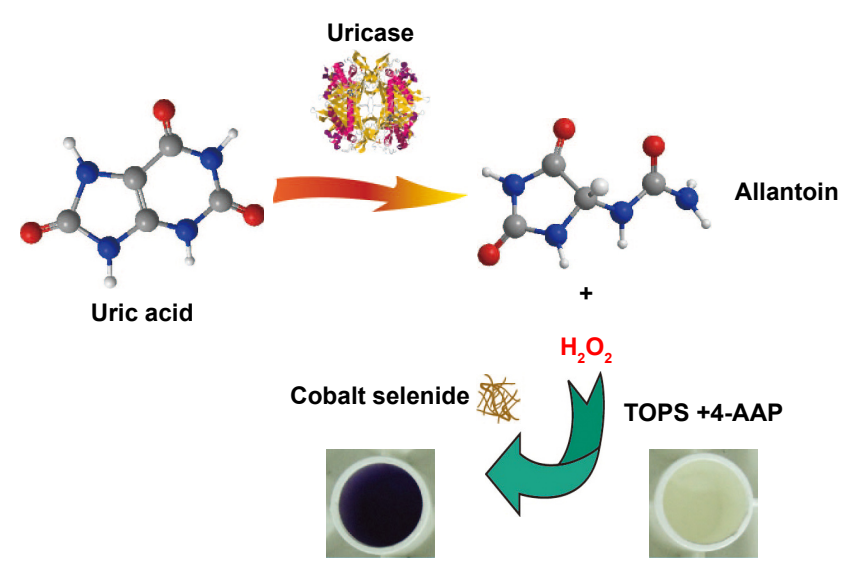

Scheme I Schematic illustration of the colorimetric assay for the detection of uric acid.

Abbreviations: 4-AAP, 4-aminoantipyrine; TOPS, N-ethyl-N-(3-sulfopropyl)-3methylaniline sodium salt.

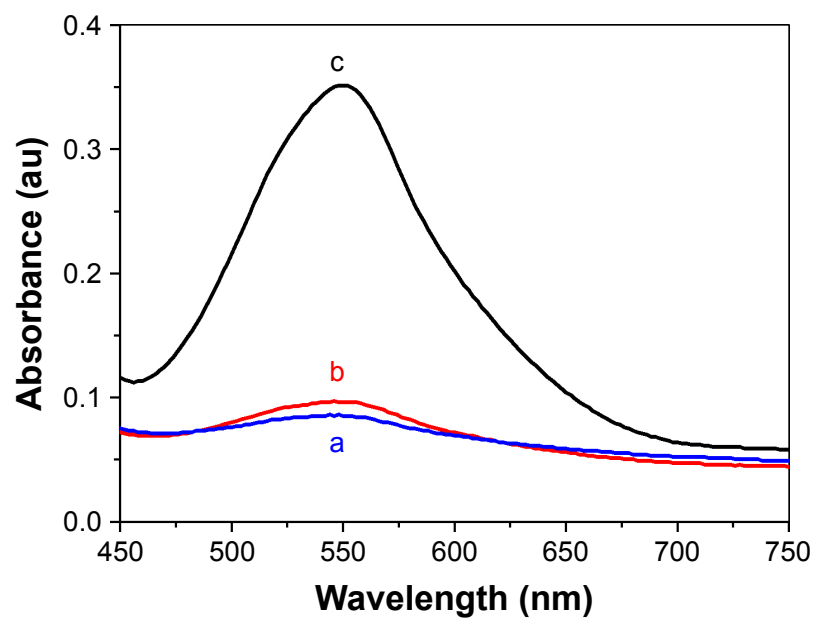

Figure 5 UV/visible spectra of the colorimetric sensor in the presence of (a) uricase, (b) uric acid, and (c) uricase + uric acid. Abbreviation: UV, ultraviolet.

UA sensing approach was compared to those of other methods based on peroxidase mimics reported in recent years. ${ }^{23,28}$ The developed sensor showed a wide linear range, good sensitivity, and relative low limit of detection. ${ }^{23,28}$

To identify the selectivity of the proposed UA sensor, responses in the presence of creatinine, ascorbic acid, glucose, cholesterol, and triglyceride were studied. As can be seen from Figure $6 \mathrm{~B}$, the absorbance at $550 \mathrm{~nm}$ was negligible even when the concentrations of the alternative substrates were 10 times higher than that of UA. The color difference can be easily distinguished with the naked eye, indicating that the developed colorimetric method exhibited high selectivity toward UA.

\section{Analysis of human serum samples}

To evaluate the possible application of the sensing system to clinical analysis, the developed method was applied to the determination of UA in human serum samples. Table 1 lists the UA content in three human serum samples determined using both our proposed method and the routine clinical method. In the routine clinical method, the UA assay was performed using a Beckman Coulter (Beckman Coulter, Inc., Brea, CA, USA) automatic analyzer using its instrument-adapting reagents, calibrators, and control solution. The results of the two-sample $t$-test and $F$-test performed at the $95 \%$ confidence level demonstrated that the two approaches did not provide significantly different results. The practical applicability of the proposed method was further verified through standard addition experiments. The results showed that the data determined using the UA sensor were in good agreement with the amount of UA added 

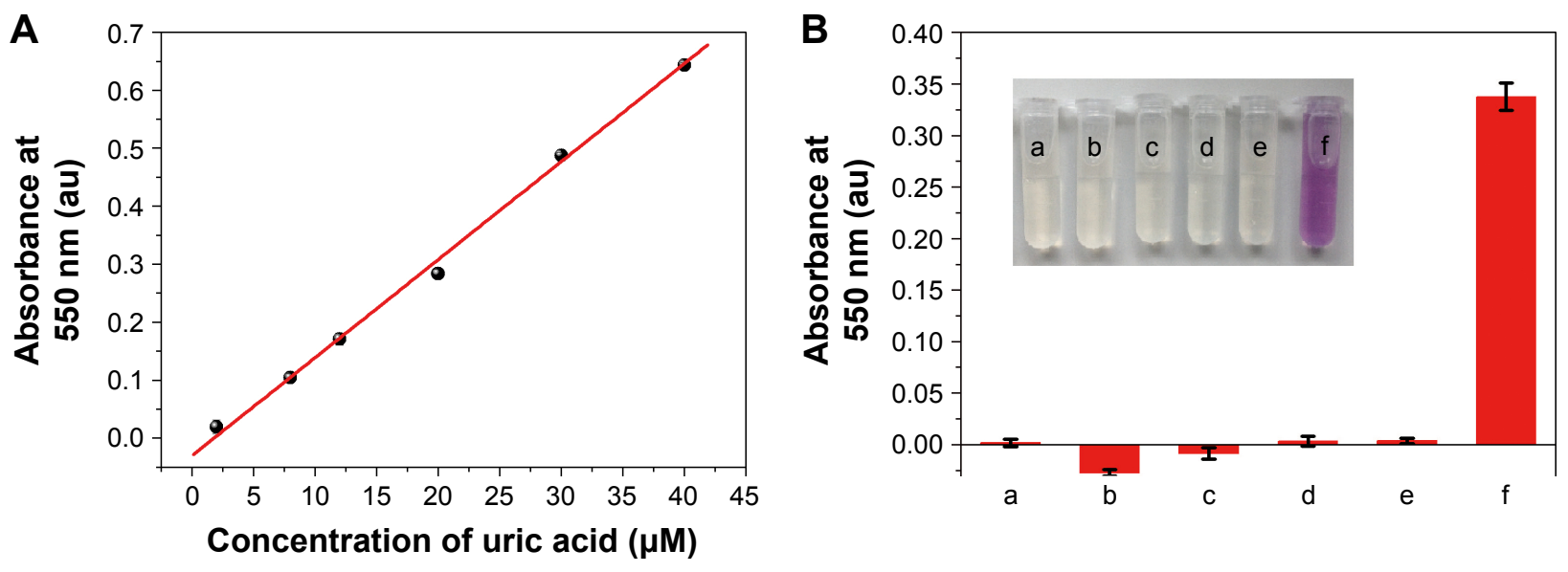

Figure 6 (A) Linear calibration plot for uric acid and (B) selectivity of the assay toward uric acid.

Notes: (a-f) Represent glucose, ascorbic acid, creatinine, cholesterol, triglyceride, and uric acid, respectively. The concentration of uric acid was $25 \mu \mathrm{M}$, while those of other solutes were $250 \mu \mathrm{M}$. Inset shows the photographs of the corresponding solutions.

to the human serum samples. The recoveries of UA from the spiked samples ranged from $100.5 \%$ to $103.2 \%$. This proves that this new method is suitable and satisfactory for UA analysis in clinical applications.

\section{Conclusion}

We found that nanocrystalline cobalt selenide fabricated via a solvothermal method possesses intrinsic peroxidaselike activity. The catalysis is dependent on temperature, $\mathrm{pH}$, and concentration of $\mathrm{H}_{2} \mathrm{O}_{2}$, similar to HRP catalysis. Kinetic analysis reveals that the catalysis followed a typical Michaelis-Menten model. Based on the intrinsic peroxidaselike activity of nanocrystalline cobalt selenide, a colorimetric UA sensor was constructed. $\mathrm{H}_{2} \mathrm{O}_{2}$ could be generated by the reaction between UA and oxygen in the presence of uricase. TOPS/4-AAP then reacted with $\mathrm{H}_{2} \mathrm{O}_{2}$ in the presence of nanocrystalline cobalt selenide as a catalyst to produce a purple product. Under optimum conditions, the assay had a linear range from 2.0 to $40 \mu \mathrm{M}$ and a detection limit of $0.5 \mu \mathrm{M}$. Satisfactory results were obtained when it was applied in the detection of UA in human serum. Therefore, we believe that this approach could be a promising candidate for bioanalysis and clinical diagnosis.

Table I Determination of uric acid in human serum samples

\begin{tabular}{lllll}
\hline Sample & \multicolumn{2}{l}{ Uric acid level, $\mu$ M, mean \pm SD } & F-test & t-test \\
\cline { 2 - 3 } & $\begin{array}{l}\text { Proposed } \\
\text { method }(\mathbf{n}=\mathbf{3})\end{array}$ & $\begin{array}{l}\text { Routine clinical } \\
\text { method }(\mathbf{n}=\mathbf{3})\end{array}$ & & \\
\hline 1 & $402.0 \pm 9.0$ & $408.3 \pm 15.3$ & 1.6 & 0.62 \\
2 & $179.7 \pm 15.9$ & $173.3 \pm 3.2$ & 5.5 & 0.68 \\
3 & $241.7 \pm 4.5$ & $236.0 \pm 15.4$ & 4.1 & 0.62 \\
\hline
\end{tabular}

Note: $F_{0.05,2,2}=19.00, t_{0.05,4}=2.776$.

Abbreviation: SD, standard deviation.

\section{Acknowledgment}

This work was financially supported by the Science and Technology Project of Quanzhou (2015Z37), the Youth Scientific Research Project of Fujian Province Health and Family Planning Commission (2016-2-48), and the National Natural Science Foundation of China (21175023).

\section{Disclosure}

The authors report no conflicts of interest in this work.

\section{References}

1. He SB, Deng HH, Liu AL, et al. Synthesis and peroxidase-like activity of salt-resistant platinum nanoparticles by using bovine serum albumin as the scaffold. Chem CatChem. 2014;6(6):1543-1548.

2. Gao LZ, Zhuang J, Nie L, et al. Intrinsic peroxidase-like activity of ferromagnetic nanoparticles. Nat Nanotechnol. 2007;2(9) 577-583.

3. Andre R, Natalio F, Humanes $\mathrm{M}$, et al. $\mathrm{V}_{2} \mathrm{O}_{5}$ nanowires with an intrinsic peroxidase-like activity. Adv Funct Mater. 2011;21:501-509.

4. Chen YJ, Cao HY, Shi WB, Liu H, Huang YM. Fe-Co bimetallic alloy nanoparticles as a highly active peroxidase mimetic and its application in biosensing. Chem Commun. 2013;49(44):5013-5015.

5. Hu AL, Liu YH, Deng HH, et al. Fluorescent hydrogen peroxide sensor based on cupric oxide nanoparticles and its application for glucose and L-lactate detection. Biosens Bioelectron. 2014;61: 374-378.

6. Zhang LN, Deng HH, Lin FL, et al. In situ growth of porous platinum nanoparticles on graphene oxide for colorimetric detection of cancer cells. Anal Chem. 2014;86(5):2711-2718.

7. Sun HJ, Zhao AD, Gao N, Li K, Ren JS, Qu XG. Deciphering a nanocarbon-based artificial peroxidase: chemical identification of the catalytically active and substrate-binding sites on graphene quantum dots. Angew Chem Int Ed Edit. 2015;54(24):7176-7180.

8. Wu GW, He SB, Peng HP, et al. Citrate-capped platinum nanoparticle as a smart probe for ultrasensitive mercury sensing. Anal Chem. 2014; 86(21):10955-10960

9. Wang GL, Xu XF, Qiu L, Dong YM, Li ZJ, Zhang C. Dual responsive enzyme mimicking activity of $\mathrm{AgX}(\mathrm{X}=\mathrm{Cl}, \mathrm{Br}, \mathrm{I})$ nanoparticles and its application for cancer cell detection. ACS Appl Mater Interfaces. 2014;6(9):6434-6442. 
10. He SB, Wu GW, Deng HH, et al. Choline and acetylcholine detection based on peroxidase-like activity and protein antifouling property of platinum nanoparticles in bovine serum albumin scaffold. Biosens Bioelectron. 2014;62:331-336.

11. Lin YH, Ren JS, Qu XG. Nano-gold as artificial enzymes: hidden talents. Adv Mater. 2014;26(25):4200-4217.

12. Lien CW, Tseng YT, Huang CC, Chang HT. Logic control of enzymelike gold nanoparticles for selective detection of lead and mercury ions. Anal Chem. 2014;86(4):2065-2072.

13. Wei H, Wang E. Nanomaterials with enzyme-like characteristics (nanozymes): next-generation artificial enzymes. Chem Soc Rev. 2013; 42(14):6060-6093.

14. Xie JX, Zhang XD, Wang H, Zheng HZ, Huang YM. Analytical and environmental applications of nanoparticles as enzyme mimetics. $\operatorname{Tr} A C$ Trend Anal Chem. 2012;39:114-129.

15. Wang XY, Hu YH, Wei H. Nanozymes in bionanotechnology: from sensing to therapeutics and beyond. Inorg Chem Front. 2016;3:41-60.

16. Puddu P, Puddu GM, Cravero E, Vizioli L, Muscari A. The relationships among hyperuricemia, endothelial dysfunction, and cardiovascular diseases: molecular mechanisms and clinical implications. J Cardiol. 2012;59(3):235-242.

17. Zhang FF, Li CX, $\mathrm{Li} \mathrm{XH}$, et al. ZnS quantum dots derived a reagentless uric acid biosensor. Talanta. 2006;68(4):1353-1358.

18. Yu JH, Wang SM, Ge L, Ge SG. A novel chemiluminescence paper microfluidic biosensor based on enzymatic reaction for uric acid determination. Biosens Bioelectron. 2011;26(7):3284-3289.

19. Noroozifar M, Khorasani-Motlagh M, Jahromi FZ, Rostami S. Sensitive and selective determination of uric acid in real samples by modified glassy carbon electrode with holmium fluoride nanoparticles/multi-walled carbon nanotube as a new biosensor. Sens Actuators B Chem. 2013; 188:65-72.
20. Dai XH, Fang X, Zhang CM, Xu RF, Xu B. Determination of serum uric acid using high-performance liquid chromatography (HPLC)/ isotope dilution mass spectrometry (ID-MS) as a candidate reference method. J Chromatogr B Analyt Technol Biomed Life Sci. 2007; 857(2):287-295.

21. Zhao S, Wang J, Ye F, Liu YM. Determination of uric acid in human urine and serum by capillary electrophoresis with chemiluminescence detection. Anal Biochem. 2008;378(2):127-131.

22. Zhao HH, Wang ZH, Jiao X, Zhang LC, Lv Y. Uricase-based highly sensitive and selective spectrophotometric determination of uric acid using BSA-stabilized Au nanoclusters as artificial enzyme. Spectrosc Lett. 2012;45(7):511-519.

23. Lu JY, Xiong YH, Liao CJ, Ye FG. Colorimetric detection of uric acid in human urine and serum based on peroxidase mimetic activity of MIL-53(Fe). Anal Methods. 2015;7:9894-9899.

24. Liu Y, Cheng H, Lyu M, et al. Low overpotential in vacancy-rich ultrathin $\mathrm{CoSe}_{2}$ nanosheets for water oxidation. J Am Chem Soc. 2014; 136(44):15670-15675.

25. Masud J, Swesi AT, Liyanage WP, Nath M. Cobalt selenide nanostructures: an efficient bifunctional catalyst with high current density at low coverage. ACS Appl Mater Interfaces. 2016;8(27):17292-17302.

26. Zhan JH, Yang XG, Li SD, Xie Y, Yu WC, Qian YT. Synthesis of nanocrystalline cobalt selenide in nonaqueous solvent. J Solid State Chem. 2000;152(2):537-539.

27. Zhang W, Liu XY, Walsh D, Yao SY, Kou Y, Ma D. Caged-proteinconfined bimetallic structural assemblies with mimetic peroxidase activity. Small. 2012;8(19):2948-2953.

28. Tang YR, Yu Z, Rui L, Ying-Ying SU, Yi L. Application of $\mathrm{NaYF}_{4}: \mathrm{Yb}$, Er nanoparticles as peroxidase mimetics in uric acid detection. Chin J Anal Chem. 2013;41(3):330-336.
International Journal of Nanomedicine

\section{Publish your work in this journal}

The International Journal of Nanomedicine is an international, peerreviewed journal focusing on the application of nanotechnology in diagnostics, therapeutics, and drug delivery systems throughout the biomedical field. This journal is indexed on PubMed Central, MedLine, CAS, SciSearch ${ }^{\circledR}$, Current Contents ${ }^{\circledR} /$ Clinical Medicine,

\section{Dovepress}

Journal Citation Reports/Science Edition, EMBase, Scopus and the Elsevier Bibliographic databases. The manuscript management system is completely online and includes a very quick and fair peer-review system, which is all easy to use. Visit http://www.dovepress.com/ testimonials.php to read real quotes from published authors. 